\title{
Uso de aditivos e tempo de abertura dos silos em silagens de estilosantes campo grande
}

\author{
Use of additives and opening time of the silos in silage of campo grande stylosanthes
}

\author{
SILVA, Mábio Silvan José da ${ }^{1 *}$; JOBIM, Clóves Cabreira ${ }^{1}$; NASCIMENTO, Willian \\ Gonçalves do ${ }^{2}$; FERREIRA, Geane Dias Gonçalves ${ }^{2}$; OLIVEIRA, Marcos Rogério ${ }^{1}$
}

${ }^{1}$ Universidade Estadual de Maringá, Departamento de Zootecnia, Maringá, Paraná, Brasil.
${ }^{2}$ Universidade Federal Rural de Pernambuco, Departamento de Zootecnia, Garanhuns, Pernambuco, Brasil.
*Endereço para correspondência: mabiosilvan@zootecnista.com.br; mabio.dasilva@lusignan.inra.fr

\section{RESUMO}

Objetivou-se avaliar o potencial de utilização do estilosantes campo grande na forma de silagem, através do valor nutritivo de silagens a vácuo, submetidas a diferentes tempos de abertura e uso de aditivos. Utilizou-se um delineamento inteiramente casualizado em esquema fatorial 4 $\mathrm{x} 4$, sendo quatro tratamentos: sem inoculante; com inoculante; com inoculante mais uréia e apenas com uréia, com quatro tempo de abertura $(14,28,42$ e 56 dias) e quatro repetições. Observou-se que as silagens sem inoculante apresentaram menores valores de $\mathrm{pH}$ e de temperatura, em relação aos demais tratamentos. Todas as silagens apresentaram maiores índices de recuperação da matéria seca no primeiro tempo de abertura, diminuindo posteriormente. As silagens de estilosantes apresentaram altas concentrações de proteína bruta, em média $167,30 \mathrm{~g} / \mathrm{kg}$ de $\mathrm{MS}$, sendo os maiores valores encontrados nas silagens com adição de uréia. As silagens sem o uso de aditivo apresentaram melhor composição químico-bromatológica, em relação aos demais tratamentos com aditivos, sendo observados valores médios de $539,17 \mathrm{~g} / \mathrm{kg}$ e $665,79 \mathrm{~g} / \mathrm{kg}$ de MS, para as concentrações de nutrientes digestíveis totais e digestibilidade "in vitro" da matéria seca, respectivamente. O estilosantes campo grande apresenta potencial para ser utilizado na forma de silagem.

Palavras-chave: composição, digestibilidade "in vitro" da matéria seca, inoculante, silagem a vácuo, valor nutritivo

\section{SUMMARY}

The aim of this study was to evaluate the potential use of Stylosanthes spp. cv. Campo Grande in silage form, through of the nutritive value of vacuum packed silages, under different opening times and use of additives. It was used a completely randomized design in factorial scheme 4 x 4, with four treatments: no inoculant; with inoculant; with inoculant plus urea and urea only, with four opening time (14, 28,42 and 56 days) and four replications. It was observed that the silages no inoculant had lower values of $\mathrm{pH}$ and temperature, compared to other treatments. All silages had higher dry matter recovery in the first time of the opening, decreasing thereafter. The stylosanthes silages showed high concentrations of crude protein, on average $167.30 \mathrm{~g} / \mathrm{kg} \mathrm{DM}$, with the largest values found in silage with urea addition. The silage without additive showed better chemical composition, compared to other treatments with additives, being observed mean values of 539.17 and $665.79 \mathrm{~g} / \mathrm{kg}$ DM for concentrations of total digestible nutrients and "in vitro" dry matter digestibility, respectively. The campo grande stylosanthes presents potential to be used in the form of silage.

Keywords: composition, inoculant, "in vitro" dry matter digestibility, nutritive value, vacuum packed silage 


\section{INTRODUÇ̃̃̃O}

Desde o seu lançamento no ano de 2000, o uso do estilosantes Campo Grande (ECG) tem aumentado continuamente devido ao seu desempenho superior e desenvolvimento da tecnologia de produção (FERNANDES et al., 2005), sendo, na atualidade, a principal leguminosa usada em sistemas de pastejo nos cerrados do Brasil (RIBEIRO et al., 2011a).

Apesar do elevado valor nutritivo do ECG (RIBEIRO et al., 2011b), um problema encontrado nas leguminosas é a baixa ensilabilidade, que ocorre devido aos baixos teores de carboidratos solúveis (CS) e de matéria seca (MS), associado a alta capacidade tampão (CT), podendo comprometer a qualidade final da silagem (JOBIM, 2008).

De acordo com Ávila et al. (2011), os aditivos a base de inoculantes microbianos são considerados benéficos por produzirem ácidos que diminuem o $\mathrm{pH}$, contudo, eles podem ser prejudiciais quando degradam proteínas, produzem compostos tóxicos para os animais e até para humanos, ou quando competem com microrganismos benéficos pelo substrato, agravando a qualidade da silagem. Desta forma, o tempo de permanência da vedação do silo tem que ser suficiente para que ocorra o processo de fermentação, com abaixamento do $\mathrm{pH}$ a níveis que impeçam o crescimento de microrganismos indesejáveis (PINTO et al., 2007).

Segundo Neumann et al. (2011) as silagens produzidas no Brasil apresentam índices de qualidade abaixo das expectativas do que se poderia considerar um volumoso de qualidade satisfatória. Neste contexto, o uso de aditivos em silagens é fruto de vários estudos, os quais buscam melhorar o padrão fermentativo.
A avaliação da eficácia de uso de aditivos em silagens, geralmente é realizada em silos de escala laboratorial, por permitir uma estimativa confiável de forma rápida e de baixo custo (MICKAN et al., 2004; HOEDTKE \& ZEYNER, 2011). Atualmente, o uso de silagens a vácuo ganhou destaque, sendo utilizado em vários estudos, tanto em escala laboratorial, como em escala de fazenda (MOSS et al., 2002; JOHNSON et al., 2005; WALKER \& FORSTER JÚNIOR, 2008; HOEDTKE \& ZEYNER, 2011).

Devido ao escasso número de estudos com silagens de leguminosas tropicais, objetivou-se avaliar, em silos laboratoriais a vácuo, o efeito do uso de aditivos e a influência do tempo de abertura do silo, nas qualidades das silagens de estilosantes Campo Grande.

\section{MATERIAL E MÉTODOS}

O experimento de campo foi desenvolvido na Fazenda Experimental da Universidade Estadual de Maringá, Paraná, Brasil.

Foram avaliadas as silagens de estilosantes (Stylosanthes spp. cv. Campo Grande - ECG) submetidas a diferentes aditivos (inoculante microbiano, Silobac ${ }^{\circledR}$ e um aditivo nutriente, uréia) e diferentes tempos de abertura. $\mathrm{O}$ delineamento experimental utilizado foi inteiramente casualizado em esquema fatorial $4 \times 4$, sendo quatro tratamentos (silagem de estilosantes sem inoculante - SSI; silagem de estilosantes com $0,01 \mathrm{~g} / \mathrm{kg}$ de inoculante - SCI; silagem de estilosantes com $0,01 \mathrm{~g} / \mathrm{kg}$ de inoculante $+5 \mathrm{~g} / \mathrm{kg}$ de uréia $-\mathrm{SCIU}$; e silagem de estilosantes com $5 \mathrm{~g} / \mathrm{kg}$ de uréia - SCU), com quatro tempos de abertura (14, 28, 42 e 56 dias) e quatro repetições cada. 
O estilosantes foi obtido da rebrota de uma área de 1 (um) hectare, implantado durante o mês de outubro de 2009, utilizada em experimentos anteriores.

O estilosantes foi colhido no estado de pré-florecimento (Tabela 1 e Tabela 2), com uso de ensiladeira modelo JF 90Z10, regulada para atingir um tamanho médio de partícula de aproximadamente $2,5 \mathrm{~cm}$. Para a aplicação, o inoculante Silobac ${ }^{\circledR}$ foi diluído, em água destilada, na proporção de $0,5 \mathrm{~g} / \mathrm{L}$ e a uréia foi aplicada diretamente na forragem a ser ensilada.

Tabela 1. Composição químico-bromatológica (g/kg de MS) e digestibilidade "in vitro" da matéria seca (DIVMS) do Stylosanthes spp. cv. Campo Grande

\begin{tabular}{cccccccccc}
\hline MS & MM & PB & FDN & FDA & LIG & NIDN & NIDA & NDT & DIVMS \\
\hline 265,18 & 66,61 & 166,53 & 584,13 & 422,14 & 118,62 & 9,32 & 2,53 & 526,88 & 662,53 \\
\hline
\end{tabular}

$\mathrm{MS}=$ matéria seca $(\mathrm{g} / \mathrm{kg}$ de $\mathrm{MN}) ; \mathrm{MM}=$ matéria mineral; $\mathrm{PB}=$ proteína bruta; $\mathrm{EE}=$ extrato etéreo; FDN = fibra em detergente neutro; FDA = fibra em detergente ácido; LIG = lignina; NIDN = nitrogênio insolúvel em detergente neutro; NIDA = nitrogênio insolúvel em detergente ácido e NDT $=$ nutrientes digestíveis totais.

Tabela 2. Frações de carboidratos $(\mathrm{g} / \mathrm{kg}$ de CHT) do Stylosanthes spp. cv. Campo Grande

\begin{tabular}{lccc}
\hline CHT & $\mathrm{A}+\mathrm{B}_{1}$ & $\mathrm{~B}_{2}$ & $\mathrm{C}$ \\
\hline 751,3 & 300,02 & 321,02 & 378,95 \\
\hline CHT = carboidratos totais $(\mathrm{g} / \mathrm{kg}$ de $\mathrm{MS}) ; \mathrm{A}+\mathrm{B}_{1}$, \\
$\mathrm{B}_{2}$ e $\mathrm{C}=$ Frações dos carboidratos.
\end{tabular}

Após a mistura do ECG com os diferentes aditivos, as amostras foram ensiladas a vácuo $(500 \mathrm{~g}$ de forragem/silo) em sacos plásticos (Nylon-poli, 16 micras, com $25 \mathrm{~cm}$ de largura $\mathrm{x} 35 \mathrm{~cm}$ de comprimento), com o uso de uma embaladora a vácuo (Tecmaq TM-280) para retirada do ar e selagem dos silos experimentais, de forma a obter uma densidade média de $600 \mathrm{~kg} / \mathrm{m}^{3}$ da massa ensilada. Os silos foram acondicionados em uma caixa e armazenados em temperatura ambiente. Os silos foram abertos aos 14; 28; $42 \mathrm{e}$ 56 dias, e realizadas as mensurações de temperatura no interior das silagens e no ambiente com uso de termômetro digital (modelo GULTERM 1001), bem como, determinado o $\mathrm{pH}$ das silagens com uso de potenciômetro (KUNG JÚNIOR. et al., 1984). Foram retiradas amostras, e feita a pré-secagem destas, para a determinação das perdas na massa ensilada e composição das silagens.

Avaliaram-se as perdas quantitativas e qualitativas das silagens de estilosantes, sendo as perdas quantitativas, expressas como recuperação da matéria seca (RMS), calculadas pela diferença no conteúdo de MS inicial e final dos silos, em relação à quantidade de $\mathrm{MS}$ da forragem ensilada, conforme equação descrita por Jobim et al. (2007). As medidas de perdas de qualidade foram estimadas tendo como referência a composição químico-bromatológica da forragem no momento do corte e os valores obtidos nas silagens.

Após abertas, todas as silagens foram pré-secas em estufa de circulação forçada de ar por um período de $72 \mathrm{~h}$ a $55^{\circ} \mathrm{C}$, sendo as amostras moídas a $1 \mathrm{~mm}$, em moinho de faca tipo Willey. Em laboratório, foram determinados os teores de MS, proteína (PB), extrato etéreo (EE) e matéria orgânica (MO) segundo métodos descritos por Silva \& Queiroz (2002). A determinação da 
fibra em detergente neutro (FDN), fibra em detergente ácido (FDA), nitrogênio insolúvel em detergente neutro (NIDN), nitrogênio insolúvel em detergente ácido (NIDA) e lignina (LIG) foram obtidos de acordo com Van Soest et al. (1991). Os valores de proteína insolúvel em detergente neutro (PIDN) e proteína insolúvel em detergente ácido (PIDA) foram calculados multiplicando-se os valores de NIDA e NIDN por 6,25, respectivamente. Os valores de carboidratos totais (CHT) foram calculados pela equação $\mathrm{CHT}=\mathrm{MO}-$ $(\mathrm{EE}+\mathrm{PB})$ e os nutrientes digestíveis totais (NDT), segundo as equações do NRC (2001). NDT $=\{0,98 \times(100-$ $[(\mathrm{FDN}-\mathrm{NIDN})+\mathrm{PB}+\mathrm{EE}+\mathrm{MM}])\}+$ $\left\{\mathrm{PB} \times \exp { }^{[-1,2 \times(\mathrm{NIDA} / \mathrm{PB})]}\right\}+\{0,75 \mathrm{x}$ $[(\mathrm{NIDN}-\mathrm{FDN})-\mathrm{LIG}] \mathrm{x}[1-$ $\left.\left.(\mathrm{LIG} /(\mathrm{NIDN}-\mathrm{FDN}))^{0,667}\right]\right\}+\mathrm{DEE}$, sendo $\mathrm{DEE}=\% \mathrm{EE}$, porém, quando a $\% \mathrm{EE}<1, \mathrm{DEE}=0$. Determinou-se ainda o fracionamento das frações dos carboidratos, sendo que a fração $\mathrm{C}$ foi determinada pela fórmula descrita por Sniffen et al. (1992), C = (100 x FDN $(\% \mathrm{MS}) \quad \mathrm{x} \quad 0,01 \quad \mathrm{x}$ LIG $(\% \mathrm{FDN}) \quad \mathrm{x}$ $2,4 / \mathrm{CHT}(\% \mathrm{MS})$ ); a fração $\mathrm{B}_{2}$ foi obtida pela equação $\mathrm{B}_{2}=100 \times((\mathrm{FDN}(\% \mathrm{MS})$ - PIDN(\%PB) x 0,01 x $\mathrm{PB}(\% \mathrm{MS}))-$ FDN $(\%$ MS $)$ x 0,01 x $\operatorname{LIG}(\%$ FDN $) \times$ $2,4))) / \mathrm{CHT}(\% \mathrm{MS})$ e a fração $\mathrm{A}+\mathrm{B}_{1}$ foi determinada pela diferença entre 100 $\left(\mathrm{C}+\mathrm{B}_{2}\right)$.

A digestibilidade "in vitro" da MS (DIVMS) foi obtida segundo a metodologia descrita por Tilley \& Terry (1963), seguindo as modificações descritas por Holden (1999), com uso do equipamento Daisy II (ANKOM technology).

Os dados obtidos foram submetidos à análise de variância e análise de regressão utilizando o programa estatístico SAS 9.2 (STATISTICAL ANALYSIS SYSTEM, 2009), e as diferenças entre as médias analisadas pelo teste de Tukey $(\mathrm{P}<0,05)$.

$\mathrm{O}$ modelo estatístico utilizado foi: $\mathrm{Y}_{\mathrm{ij}}=\mu+\mathrm{S}_{\mathrm{i}}+\mathrm{E}_{\mathrm{j}}+\mathrm{S}_{\mathrm{i}} \mathrm{E}_{\mathrm{j}}+\varepsilon_{\mathrm{ijk}}$, em que: $\mathrm{Y}_{\mathrm{ij}}=$ valor observado nas silagens submetidas aos diferentes aditivos $\mathrm{i} e$ tempo de abertura $\mathrm{j} ; \mu=$ constante geral referentes a todas observações; $\mathrm{S}_{\mathrm{i}}=$ efeito do i-ésimo aditivo na silagem, onde $\mathrm{i}=1$ a $4 ; \mathrm{E}_{\mathrm{j}}=$ efeito do j-ésimo período de abertura na silagem, onde $\mathrm{j}=$ $1 \mathrm{a} \mathrm{4;} \mathrm{S}_{\mathrm{i}} \mathrm{E}_{\mathrm{j}}=$ efeito da interação entre o i-ésimo aditivo com o j-ésimo período de abertura; $\varepsilon_{\mathrm{ijk}}=$ erro aleatório associado a cada observação.

\section{RESULTADOS E DISCUSSÃO}

Observou-se que as silagens de estilosantes sem inoculante (SSI) diferiram estatisticamente $(\mathrm{P}<0,05)$ dos demais tratamentos, apresentando os menores valores de $\mathrm{pH}$ (média de 4,83), independente do tempo de abertura dos silos, exceto aos 14 dias, no qual as silagens que receberam o inoculante Silobac ${ }^{\circledR}$ (SCI) apresentaram menor valor (Figura 1). Isto pode ser em função da predominância da atuação das cepas presentes, uma vez que os Lactobacillus plantarum, Streptococcus faecium e Lactobacillus sp. presente no inoculante, favorece uma rápida $\mathrm{e}$ dominante produção de ácido lático, diminuindo o pH (KUNG JÚNIOR et al., 2003; SCHMIDT et al., 2009).

Nos demais tempos de abertura dos silos (28, 42 e 56 dias), não foram observadas diferenças significativas $(\mathrm{P}>0,05)$ de $\mathrm{pH}$, dentro dos tratamentos, em relação ao período anterior (14 dias). Nos tratamentos com inoculante acrescidos de uréia (SCIU) e apenas com uréia (SCU), as silagens apresentaram os maiores valores de $\mathrm{pH}$, alcançando valores máximos de 6,11 e 
6,59, respectivamente. No entanto, enquanto o comportamento foi crescente na SCIU, o $\mathrm{pH}$ da SCU apresentou comportamento inverso. Isso é evidente devido a ação da uréia, por essa ser hidrolisada pela ação da urease, liberando a amônia $\left(\mathrm{NH}_{3}\right)$, diminuindo a velocidade de abaixamento do $\mathrm{pH}$ e favorecendo o prolongamento do tempo de fermentação (KUNG JÚNIOR et al., 2003), o que ocasiona maior utilização dos substratos fermentescíveis do material ensilado, afetando a qualidade final da silagem.

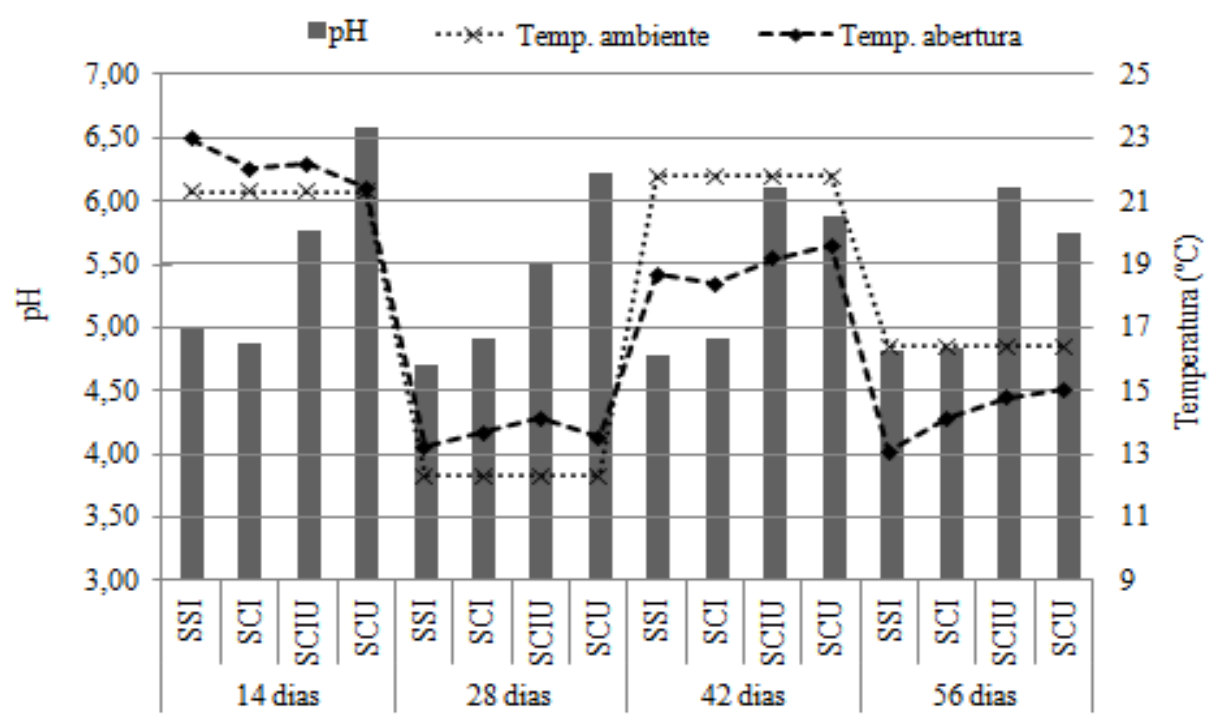

Figura 1. Valores de $\mathrm{pH}$, temperatura ambiente e temperatura das silagens de Stylosanthes spp. cv. Campo Grande em função dos diferentes tempos de abertura dos silos e tratamentos

Jacobs Dias et al. (2010) observaram valores de $\mathrm{pH}$, em silagens da planta da soja em fase de desenvolvimento da vagem, entre 5,2 a 5,4, sendo estes superiores aos encontrados nas silagens sem inoculante e com inoculante, as quais apresentaram $\mathrm{pH}$ médio de 4,83 e 4,88 , respectivamente. Valores semelhantes foram encontrados, em silagens de ECG sem aditivos, por Ribeiro et al. (2011a), que constataram valor de 4,74. Neste mesmo experimento, os autores obtiveram maiores valores de $\mathrm{pH}$ em silagens acrescidas de inoculante bacteriano, em relação as não inoculadas.

Quanto a temperatura, observou-se que nos dois primeiros tempos de abertura, as silagens apresentaram temperaturas superiores a ambiente, o que se deve a intensa atividade microbiológica, porém não ultrapassando em mais de $2^{\circ} \mathrm{C}$. Assim, enquanto o oxigênio ainda estiver presente, mesmo que em baixas concentrações, a energia gerada pelos processos de respiração e oxidação dos substratos é, em parte, utilizada para suprir as necessidades energéticas das células, sendo que o excedente é liberado na forma de calor, aumentando assim a temperatura no interior dos silos (McDONALD et al., 1991).

Após os 42 dias de armazenagem, observou-se menores temperaturas nas silagens, em relação a temperatura ambiente, o que pode ter ocorrido 
devido a menor atividade microbiana, em decorrência da estabilização da silagem. McDonald et al. (1991) relatou que em condições de anaerobiose, as plantas superiores convertem o piruvato formado pelo processo de glicólise em dióxido de carbono $\left(\mathrm{CO}_{2}\right)$ e etanol, de forma que, nesta via metabólica, uma grande quantidade da energia do piruvato é armazenada como molécula de etanol, e cerca de apenas $6 \%$ é perdido como calor.

As silagens que foram tratadas com uréia (SCIU e SCU) apresentaram maiores valores de temperatura que as demais (SSI e SCI) nos três últimos tempos de abertura, o que é resultado do prolongamento do tempo da atividade fermentativa na massa ensilada, já que o $\mathrm{pH}$ é reduzido lentamente nessas condições, uma vez que as concentrações de ácido lático e ácido acético são reduzidas, bem como, a formação do etanol é menor, ocasionando a maior liberação de energia na forma de calor.
Analisando a recuperação da matéria seca - RMS (Tabela 3), observa-se que as silagens sem inoculante e as com uréia, bem como, as silagens com inoculante aos 48 e 56 dias, apresentaram os melhores índices $(\mathrm{P}<0,05)$. Jacobs Dias et al. (2010), observou valores médios de RMS, em silagens da planta da soja, em estágio de desenvolvimento da vagem, de $913 \mathrm{~g} / \mathrm{kg}$, sendo este inferior aos dados encontrados para as silagens sem inoculante (SSI) e para as silagens com uréia (SCU), porém superiores as médias de RMS nas silagens com inoculante (SCI) e nas silagens com inoculante e uréia (SCIU). De acordo com Rodrigues et al. (2004), em condições ótimas de fermentação, as respostas, geralmente alcançadas com os inoculantes, são inibidas. $\mathrm{O}$ alto índice de $\mathrm{RMS}$ observados neste experimento pode ser atribuído, em parte, ao melhor controle e condições nas quais as silagens foram confeccionadas, o que é possível com a utilização de silagens a vácuo.

Tabela 3. Índice de recuperação da matéria seca (RMS) nas silagens de Stylosanthes spp cv. Campo Grande em função dos diferentes tratamentos e tempos de abertura dos silos

\begin{tabular}{|c|c|c|c|c|c|c|}
\hline \multirow{2}{*}{ Tratamentos } & \multicolumn{4}{|c|}{ Tempo de Abertura (dias) } & \multirow{2}{*}{ Média } & \multirow{2}{*}{$\mathrm{CV}(\%)$} \\
\hline & 14 & 28 & 42 & 56 & & \\
\hline SSI & $977,61^{\mathrm{aA}}$ & $907,87^{\mathrm{bAB}}$ & $877,64^{\mathrm{bB}}$ & $911,29^{\mathrm{bA}}$ & 918,60 & 4,59 \\
\hline $\mathrm{SCI}$ & $916,73^{\mathrm{aB}}$ & $863,58^{\mathrm{bcBC}}$ & $839,67^{\mathrm{cBC}}$ & $885,39^{\mathrm{abAB}}$ & 876,34 & 3,74 \\
\hline SCIU & $931,21^{\mathrm{aB}}$ & $845,23^{\mathrm{bC}}$ & $804,47^{\mathrm{bC}}$ & $849,35^{\mathrm{bB}}$ & 857,56 & 6,19 \\
\hline $\mathrm{SCU}$ & $1.000,00^{\mathrm{aA}}$ & $926,70^{\mathrm{bA}}$ & $921,27^{\mathrm{bA}}$ & $925,92^{\mathrm{bA}}$ & 943,47 & 4,00 \\
\hline
\end{tabular}

Médias na mesma linha, seguidas de letras minúsculas diferentes, diferem pelo teste Tukey $(\mathrm{P}<0,05)$.

Médias na mesma coluna, seguidas de letras maiúsculas diferentes, diferem pelo teste Tukey $(\mathrm{P}<0,05)$.

$\mathrm{SSI}=$ sem inoculante; $\mathrm{SCI}=$ com inoculante; $\mathrm{SCIU}=$ com inoculante e uréia e SCU = com uréia.

Os efeitos dos tratamentos e dos diferentes tempos de abertura dos silos sobre a composição químicobromatológica das silagens, bem como a indicação da existência de interações, são apresentados na Tabela 4.
Comparando a concentração média de MS das silagens com a da planta do ECG, verificou-se uma redução na ordem de $22,97 \mathrm{~g} / \mathrm{kg}$ de $\mathrm{MN}$, que pode ser decorrente das perdas pelo processo de fermentação, que em condições 
normais alcança valores médios de $100 \mathrm{~g} / \mathrm{kg}$ de MN (JACOBS DIAS et al., 2010).

As silagens tratadas com aditivos bacterianos apresentaram menores teores de MS $(\mathrm{P}<0,05)$, constatando-se maior concentração nas silagens tratadas com uréia. $\mathrm{O}$ efeito do tempo de abertura sobre a concentração de MS provocou diminuição até a abertura aos
42 dias, ocorrendo após aumento nessas concentrações. Comportamento semelhante foi relatado por Schimidt et al. (2009), trabalhando com silagem de alfafa. Os valores médios de MS encontrados neste estudo foram superiores aos descritos por Ribeiro et al. (2011b), que registraram teores de MS na ordem de $234,20 \mathrm{~g} / \mathrm{kg}$ de $\mathrm{MN}$, em silagens de estilosantes Campo Grande.

Tabela 4. Composição químico-bromatológica (g/kg de MS) e digestibilidade "in vitro" da matéria seca (DIVMS) da silagem de Stylosanthes spp. cv. Campo Grande em função de diferentes tratamentos e tempos de abertura dos silos

\begin{tabular}{|c|c|c|c|c|c|c|c|c|c|c|c|c|}
\hline \multirow{2}{*}{ Item } & \multicolumn{4}{|c|}{ Tratamentos } & \multicolumn{4}{|c|}{ Tempo de Abertura (dias) } & \multicolumn{3}{|c|}{ Interação } & \multirow{2}{*}{$\begin{array}{l}C V \\
(\%)\end{array}$} \\
\hline & SSI & SCI & SCIU & SCU & 14 & 28 & 42 & 56 & $\mathrm{~T}$ & TA & TxTA & \\
\hline $\mathrm{MS}^{1}$ & $246,28^{b}$ & $234,81^{\mathrm{c}}$ & $230,94^{\mathrm{c}}$ & $256,80^{\mathrm{a}}$ & $257,69^{\mathrm{a}}$ & $238,59^{b}$ & $231,78^{\mathrm{c}}$ & $240,76^{\mathrm{b}}$ & $* * *$ & $* * *$ & $*$ & 1,80 \\
\hline MM & $61,39^{b}$ & $60,73^{\mathrm{b}}$ & $67,58^{\mathrm{a}}$ & $67,72^{\mathrm{a}}$ & $63,78^{\mathrm{ab}}$ & $61,54^{\mathrm{b}}$ & $66,26^{\mathrm{a}}$ & $65,84^{\mathrm{a}}$ & $* * *$ & $* * *$ & $* * *$ & 4,32 \\
\hline $\mathrm{EE}$ & $20,78^{b}$ & $20,82^{\mathrm{b}}$ & $25,14^{\mathrm{a}}$ & $24,41^{\mathrm{a}}$ & $22,21^{b}$ & $18,63^{\mathrm{c}}$ & $25,32^{\mathrm{a}}$ & $24,99^{\mathrm{a}}$ & $* * *$ & $*$ & & 7,58 \\
\hline PB & $161,03^{\mathrm{c}}$ & $155,83^{\mathrm{d}}$ & $172,99^{\mathrm{b}}$ & $179,34^{\mathrm{a}}$ & $164,42^{\mathrm{b}}$ & $164,70^{\mathrm{b}}$ & $167,31^{b}$ & $172,76^{\mathrm{a}}$ & $* * *$ & $* * *$ & $* * *$ & 2,80 \\
\hline FDN & $573,84^{b}$ & $598,54^{\mathrm{a}}$ & $587,69^{\mathrm{ab}}$ & $574,98^{\mathrm{b}}$ & $585,64^{\mathrm{a}}$ & $584,39^{\mathrm{a}}$ & $581,47^{\mathrm{a}}$ & $583,56^{\mathrm{a}}$ & $* *$ & NS & NS & 3,55 \\
\hline FDA & $418,61^{\mathrm{c}}$ & $447,67^{\mathrm{a}}$ & $453,49^{\mathrm{a}}$ & $435,80^{b}$ & $431,18^{\mathrm{c}}$ & $429,37^{\mathrm{c}}$ & $453,27^{\mathrm{a}}$ & $441,76^{\mathrm{b}}$ & $* * *$ & $* * *$ & . & 1,91 \\
\hline CHT & $756,80^{b}$ & $762,62^{\mathrm{a}}$ & $734,29^{c}$ & $728,54^{d}$ & $749,59^{\mathrm{b}}$ & $755,13^{a}$ & $741,11^{\mathrm{c}}$ & $736,41^{\mathrm{c}}$ & $* * *$ & $* * *$ & $* * *$ & 0,74 \\
\hline LIG & $120,33^{\mathrm{a}}$ & $125,04^{\mathrm{a}}$ & $123,48^{\mathrm{a}}$ & $123,31^{\mathrm{a}}$ & $130,42^{\mathrm{a}}$ & $122,86^{\mathrm{b}}$ & $116,42^{b}$ & $122,46^{\mathrm{b}}$ & NS & $*$ & $* * *$ & 5,63 \\
\hline NIDN & $6,66^{\mathrm{a}}$ & $7,07^{\mathrm{a}}$ & $5,71^{\mathrm{b}}$ & $6,09^{\mathrm{b}}$ & $6,51^{\mathrm{a}}$ & $6,33^{\mathrm{a}}$ & $6,17^{\mathrm{a}}$ & $6,52^{\mathrm{a}}$ & $* * *$ & NS & $* * *$ & 7,58 \\
\hline NIDA & $1,88^{\mathrm{b}}$ & $2,07^{\mathrm{a}}$ & $2,18^{\mathrm{a}}$ & $2,13^{\mathrm{a}}$ & $1,94^{\mathrm{b}}$ & $1,93^{\mathrm{b}}$ & $2,19^{\mathrm{a}}$ & $2,21^{\mathrm{a}}$ & $* * *$ & $* * *$ & $* * *$ & 6,36 \\
\hline NDT & $539,17^{\mathrm{a}}$ & $524,8^{\mathrm{b}}$ & $525,77^{\mathrm{b}}$ & $530,86^{\mathrm{ab}}$ & $522,24^{\mathrm{b}}$ & $528,33^{\mathrm{ab}}$ & $538,51^{\mathrm{a}}$ & $531,5^{\mathrm{ab}}$ & $* *$ & $* * *$ & $* * *$ & 1,16 \\
\hline DIVMS & $665,79^{\mathrm{a}}$ & $634,54^{b}$ & $626,52^{b}$ & $655,40^{\mathrm{a}}$ & $646,48^{\mathrm{a}}$ & $642,43^{\mathrm{a}}$ & $650,97^{\mathrm{a}}$ & $642,36^{\mathrm{a}}$ & $* * *$ & NS & $* * *$ & 2,86 \\
\hline
\end{tabular}

Médias na mesma linha, seguidas de letras diferentes, diferem entre si pelo teste Tukey $(\mathrm{P}<0,05)$.

$\mathrm{NS}=$ não significante; $* \mathrm{P}<0,05 ; * * \mathrm{P}<0,01 ; * * * \mathrm{P}<0,001$.

$\mathrm{MS}=$ matéria seca $(\mathrm{g} / \mathrm{kg}$ de $\mathrm{MN}) ; \mathrm{MM}=$ matéria mineral; $\mathrm{EE}=$ extrato etéreo; $\mathrm{PB}$ = proteína bruta; $\mathrm{FDN}=$ fibra em detergente neutro; FDA $=$ fibra em detergente ácido; $\mathrm{CHT}=$ carboidratos totais; $\mathrm{LIG}=$ lignina; NIDN = nitrogênio insolúvel em detergente neutro; NIDA = nitrogênio insolúvel em detergente ácido; NDT $=$ nutrientes digestíveis totais

•SSI = sem inoculante; SCI = com inoculante; SCIU = com inoculante mais uréia; SCU = com uréia.

Os teores de MM apresentaram pouca redução nas silagens, em relação às plantas, sendo observada a redução de $2,25 \mathrm{~g} / \mathrm{kg}$ de MS. Concentrações superiores de $\mathrm{MM} \quad(\mathrm{P}<0,05)$ foram encontradas nas silagens que receberam tratamento com uréia, no entanto, se avaliado sob o ponto de vista do tempo de abertura, observou-se pequena diminuição no dia 28, sendo após, verificado teores semelhantes a primeira data de abertura. Nas silagens que receberam inoculante, constataram-se as menores concentrações médias de MM $(\mathrm{P}<0,05)$. Porém, estas silagens apresentaram aumento nos valores de 
MM aos 42 e 56 dias de abertura após a ensilagem, refletindo a maior utilização dos compostos orgânicos e um processo de fermentação inadequado.

Segundo Ashbell (1995), o menor teor de cinzas é indicativo de melhor conservação da forragem, pois, a ocorrência de uma fermentação inadequada resulta em perdas de $\mathrm{MO}$, aumentando a participação relativa da MM na MS.

Para o EE, observou-se concentração média superior, em 7,22g/kg de MS, nas silagens, em relação ao ECG. No entanto, entre as silagens, ocorreram menores variações nos teores de $\mathrm{EE}$, de forma que as silagens que receberam a adição de uréia (SCIU e SCU) apresentaram os valores mais altos $(\mathrm{P}<0,05)$. Em relação aos diferentes tempos de abertura das silagens, observou-se resultados de EE mais elevados nos dois últimos períodos, $42 \mathrm{e}$ 56 dias.

Em relação a composição da planta ensilada, constatou-se um pequeno aumento $(\mathrm{P}>0,05)$ de $0,77 \mathrm{~g} / \mathrm{kg}$ de $\mathrm{MS}$ nas concentrações médias de $\mathrm{PB}$, este aumento foi resultante das silagens que receberam o tratamento com uréia, pois quando analisada, a planta em relação a silagem controle (SSI), observou-se o comportamento inverso, com redução média de $5,5 \mathrm{~g} / \mathrm{kg}$ de MS. Filya et al. (2007) encontrou redução de $16,25 \mathrm{~g} / \mathrm{kg}$ de MS, em silagens do primeiro corte da alfafa, superior a aqui observada. A PB apresentou-se em maiores concentrações $(\mathrm{P}<0,05)$ nos tratamentos que receberam uréia como aditivo, sendo encontrados teores de 179,34 e $172,99 \mathrm{~g} / \mathrm{kg}$ de $\mathrm{MS}$ para SCU e SCIU, respectivamente. Isto ocorreu devido à uréia ser um aditivo nutriente, o qual é rico em nitrogênio, disponibilizando-o para o metabolismo dos microrganismos, resultando tanto em maiores teores de nitrogênio não protéico como em PB de origem microbiana.
Verificou-se redução nos teores de $\mathrm{PB}$ nas silagens contendo apenas inoculante $(\mathrm{P}<0,05)$. Da mesma forma, Rodrigues et al. (2004) observaram redução de $8,4 \mathrm{~g} / \mathrm{kg}$ de MS nas concentrações de PB, em silagens de alfafa inoculada com Silobac. De acordo com Muck et al. (2007), o uso de bactérias homofermentativas, tais como L. plantarum, E. faecium e Pediococcus spp, reduz as concentrações de nitrogênio amoniacal, bem como de PB. O teor de PB também diferiu estatisticamente $(\mathrm{P}<0,05)$ em função dos tempos de abertura, sendo encontrados maiores valores aos 56 dias, onde as silagens apresentaram a média de $172,76 \mathrm{~g} / \mathrm{kg}$. Este aumento da PB ocorreu devido o efeito de diluição, pois, com o prolongamento do tempo de abertura (42 e 56 dias), observaram-se menores concentrações de carboidratos totais nas silagens, demonstrando que este foi o principal substrato utilizado na fermentação. Assim, aumentando em termos proporcionais, os teores de $\mathrm{PB}$. As concentrações de PB encontrada neste experimento, apresentaram-se superior a média encontrada por Ribeiro et al. (2011b), que foi de 135,30 $\mathrm{g} / \mathrm{kg}$ de MS.

Os valores de NIDN e de PIDN apresentaram-se menores nas silagens com adição de uréia, SCIU e SCU $(\mathrm{P}<0,05)$, no entanto, estas apresentaram maiores concentrações de NIDA e de PIDA, juntamente com a silagem apenas com inoculante (SCI). Assim, as silagens não inoculadas apresentam melhor disponibilidade da proteína.

Os teores médios de FDN das silagens foram inferiores, em aproximadamente $0,37 \mathrm{~g} / \mathrm{kg}$ de $\mathrm{MS}$, em relação ao da forragem de ECG, no entanto, as concentrações de FDA e lignina aumentaram em média 16,75 e 4,41 g/kg de MS, respectivamente, o que ocorreu, possivelmente, pela degradação parcial da hemicelulose nas silagens. 
Não houve diferença estatística $(\mathrm{P}>0,05)$ para a FDN da silagem em função do tempo de abertura dos silos, bem como da interação desses com o uso de aditivos, existindo variações apenas em função dos tratamentos, onde os maiores valores foram observados nas silagens com inoculante. Rodrigues et al. (2001) atribui uma maior concentração de FDN e de FDA, em silagens inoculadas, devido a ocorrência da queda mais acentuada no $\mathrm{pH}$, o que pode inibir a degradação parcial da hemicelulose e possivelmente da celulose no silo. No presente trabalho, observaram-se resultados de FDA semelhantes ao comportamento descrito por Rodrigues et al. (2001), os quais foram maiores $(\mathrm{P}<0,05)$ nas silagens inoculadas, além de apresentarem-se maior em função do tempo de abertura, atingindo resultados superiores de FDA aos 42 dias de abertura.

Observou-se que houve interação $(\mathrm{P}<0,05)$ entre uso de aditivos e tempo de abertura, sendo obtidos valores superiores de CHT $(\mathrm{P}<0,05)$ nas silagens tratadas apenas com inoculante (SCI), e na abertura aos 28 dias, as quais apresentaram valores de 762,62 e $755,13 \mathrm{~g} / \mathrm{kg}$ de MS, respectivamente.

Para os valores de NDT, observou-se que as silagens sem inoculante e as com uréia apresentaram os maiores valores $(\mathrm{P}<0,05)$, porém, esta última não diferindo dos demais tratamentos. As maiores concentrações de NDT nas silagens sem inoculante ocorreu devido às boas características químicobromatologicas presentes no estilosantes Campo Grande (Tabela 2), que apresentou teor médio de CHT igual a $751,30 \mathrm{~g} / \mathrm{kg}$ de $\mathrm{MS}$, sendo $4 / 5$ desse representado pelas frações $A+B_{1}$ e $B_{2}$, que são potencialmente utilizadas pelos microrganismos na silagem, principalmente a fração $A+B_{1}$, que neste caso correspondeu a aproximadamente 2/5 dos CHT.

Observou-se ainda que o maior tempo para a abertura das silagens favoreceu o aumento das concentrações de NDT, com as maiores concentrações aos 42 dias, diferindo em relação ao $14^{\circ}$ dia.

Os menores valores de DIVMS $(\mathrm{P}<0,05)$ foram encontrados nas silagens que receberam a adição do inoculante, não sendo observado efeito significativo do tempo de abertura do silo.

Os efeitos dos tratamentos e dos tempos de abertura dos silos, sobre as frações constituintes dos carboidratos nas silagens, são apresentados na Tabela 5. As concentrações das frações $A+B_{1}$ não foram influenciadas pelos diferentes tempos de abertura, no entanto, a aplicação de aditivos reduziu as suas concentrações $\quad(\mathrm{P}<0,05), \quad$ obtendo-se resultados inferiores para o uso combinado de inoculante mais uréia (SCIU).

Não houve efeito das interações $(\mathrm{P}>0,05)$ entre os diferentes aditivos $\mathrm{e}$ os tempos de abertura dos silos sobre a fração $B_{2}$. No entanto, observou-se efeito significativo $(\mathrm{P}<0,05)$ do tempo de abertura dos silos, constatando-se valores máximos da fração $\mathrm{B}_{2}$ aos 42 dias, diferindo $(\mathrm{P}<0,05)$ em relação aos menores valores, obtidos nas silagens aberta aos 14 dias. Os resultados para os períodos de abertura de 28 e 56 dias não diferiram entre si $(\mathrm{P}>0,05)$, nem entre os valores obtidos nos períodos supracitados.

As silagens que receberam uréia (SCIU e SCU) apresentaram maiores concentrações das frações $\mathrm{C}$, porém não diferindo $(\mathrm{P}>0,05)$ das silagens com inoculante (SCI), as quais diferiram $(\mathrm{P}<0,05)$ das silagens sem inoculante (SSI). O aumento na concentração da fração C em geral, ocasiona uma redução na digestibilidade do alimento, 
uma vez que representa a porção dos carboidratos que não é digerida, independente do tempo de retenção do alimento no trato gastrointestinal (SNIFFEN et al., 1992).

Observou-se que houve interações $(\mathrm{P}<0,05)$ entre tratamentos e tempos de abertura dos silos, sobre os valores de
DIVMS (Tabela 4). Não foram observados efeitos significativos, referentes apenas aos diferentes tempos de abertura, porém, observou-se efeito dos diferentes tratamentos sobre a DIVMS, sendo que os maiores valores $(\mathrm{P}<0,05)$ foram observados nas silagens sem inoculante e nas silagens com uréia.

Tabela 5. Frações de carboidratos (g/kg de CHT) da silagem de estilosantes cv. Campo Grande em função de diferentes tratamentos e tempos de abertura dos silos

\begin{tabular}{|c|c|c|c|c|c|c|c|c|c|c|c|c|}
\hline \multirow{2}{*}{ Frações } & \multicolumn{4}{|c|}{ Tratamentos } & \multicolumn{4}{|c|}{ Tempo de Abertura (dias) } & \multicolumn{3}{|c|}{ Interação } & \multirow{2}{*}{$\begin{array}{l}\text { CV } \\
(\%)\end{array}$} \\
\hline & SSI & SCI & SCIU & $\mathrm{SCU}$ & 14 & 28 & 42 & 56 & $\mathrm{~T}$ & TA & TxTA & \\
\hline CHT & $756,80^{\mathrm{b}}$ & $762,62^{\mathrm{a}}$ & $734,29^{\mathrm{c}}$ & $728,54^{\mathrm{d}}$ & $749,59^{\mathrm{b}}$ & $755,13^{\mathrm{a}}$ & $741,11^{\mathrm{c}}$ & $736,41^{\mathrm{c}}$ & $* * *$ & $* * *$ & $* * *$ & 0,74 \\
\hline $\mathrm{A}+\mathrm{B}_{1}$ & $296,82^{\mathrm{a}}$ & $273,00^{\mathrm{b}}$ & $248,07^{\mathrm{c}}$ & $262,89^{\mathrm{bc}}$ & $273,00^{\mathrm{a}}$ & $278,45^{\mathrm{a}}$ & $267,02^{\mathrm{a}}$ & $262,32^{\mathrm{a}}$ & $* * *$ & $\mathrm{NS}$ & $* *$ & 8,85 \\
\hline $\mathrm{B}_{2}$ & $321,57^{\mathrm{a}}$ & $333,48^{\mathrm{a}}$ & $348,30^{\mathrm{a}}$ & $330,74^{\mathrm{a}}$ & $309,44^{\mathrm{b}}$ & $331,02^{\mathrm{ab}}$ & $355,39^{\mathrm{a}}$ & $338,24^{\mathrm{ab}}$ & NS & $* *$ & NS & 10,46 \\
\hline $\mathrm{C}$ & $381,61^{\mathrm{b}}$ & $393,52^{\mathrm{ab}}$ & $403,63^{\mathrm{a}}$ & $406,37^{\mathrm{a}}$ & $417,56^{\mathrm{a}}$ & $390,54^{\text {bc }}$ & $377,60^{\mathrm{c}}$ & $399,44^{\mathrm{ab}}$ & * & $* * *$ & $* * *$ & 5,72 \\
\hline
\end{tabular}

Médias na mesma linha, seguidas de letras diferentes, diferem entre si pelo teste de Tukey $(\mathrm{P}<0,05)$.

$\mathrm{NS}=$ não significante; $* \mathrm{P}<0,05 ; * * \mathrm{P}<0,01 ; * * * \mathrm{P}<0,001$.

$\mathrm{CHT}=$ carboidratos totais $(\mathrm{g} / \mathrm{kg}$ de MS).

• $\mathrm{SSI}$ = sem inoculante; $\mathrm{SCI}=$ com inoculante; $\mathrm{SCIU}=$ com inoculante mais uréia; $\mathrm{SCU}=$ com uréia.

Os valores de DIVMS das silagens com uréia (SCU) diferiram em função da interação com o tempo de abertura $(\mathrm{P}<0,05)$. Observou-se que a adição do inoculante Silobac ${ }^{\circledR}$ reduziu a DIVMS das silagens de estilosantes, de 665,79 para $634,54 \mathrm{~g} / \mathrm{kg}$ de MS. Avaliando silagens de alfafa, sem inoculante e com a adição do inoculante Silobac $\AA$, Rodrigues et al. (2004) relataram valores médios de DIVMS de 665,00 e $602,10 \mathrm{~g} / \mathrm{kg}$ de $\mathrm{MS}$, respectivamente, inferiores aos encontrados no presente trabalho. Porém, o comportamento dos resultados foi semelhante, demonstrando uma redução da DIVMS, nas silagens tratadas com inoculante. Da mesma forma, Filya et al. (2007) constataram redução nos valores de digestibilidade em silagens de alfafa inoculadas com $E$. faecium, L. plantarum, e Pediococcus spp. Esta redução observada é decorrente da maior concentração de componentes voláteis, como o nitrogênio amoniacal e o etanol, presentes em silagens tratada com esse inoculante, uma vez que a metodologia para determinação da DIVMS exige a secagem prévia da amostra (RODRIGUES et al., 2004).

Neste contexto, o estilosantes cv. Campo Grande demonstra potencial para utilização na forma de silagens, por apresentar características satisfatórias de composição químico-bromatológica, de forma que, o uso de aditivos não melhorou a qualidade da silagem de estilosantes, independente do tempo de abertura dos silos. A utilização de silagens a vácuo é eficiente para as avaliações do uso de aditivos, por permitir o maior controle das condições de anaerobiose no ambiente fermentativo. 
Rev. Bras. Saúde Prod. Anim., Salvador, v.15, n.2, p.381-393 abr./jun., 2014 http://www.rbspa.ufba.br ISSN 15199940

\section{REFERÊNCIAS}

\section{ASHBELL, G. Basic principles of} preservation of forage, by-products and residues as silage or hay. Bet Dagan, Israel: Agricultural Research Organization, 1995. 58p.

ÁVILA, C.L.S.; SCHWAN, R.F.; PINTO, J.C.; CARVALHO, B.F. Potential use of native microorganisms strains of forage for silage production. In: INTERNATIONAL SYMPOSIUM ON FORAGE QUALITY AND CONSERVATION, 2., 2011, São Pedro. Proceedings... Piracicaba: Fealq, 2011. p.25-44.

FERNANDES, C.D.; GROF, B.; CHAKRABORTY, S.;

VERZIGNASSI, J.R. Estilosantes Campo Grande in Brazil: a tropical forage legume success story. Tropical Grasslands, v.39, n.4, p.223-224, 2005.

FILYA, I.; MUCK, R.E.; CONTRERAS-GOVEA, F.E. Inoculant effects on alfalfa silage: fermentation products and nutritive value. Journal of Dairy Science, v.90, n.11, p.5108-5114, 2007.

HOEDTKE, S.; ZEYNER, A. Comparative evaluation of laboratoryscale silages using standard glass jar silages or vacuum-packed model silages. Journal of Science of Food and Agriculture, v.91, p.841-849, 2011.

HOLDEN, L.A. Comparison of methods of in vitro dry matter digestibility for ten feeds. Journal of Dairy Science, v.82, n.8, p.1791-1794, 1999.
JACOBS DIAS, F.; JOBIM, C.C.; SORIANI FILHO, J.L.; BUMBIERIS JUNIOR, V.H.; POPPI, E.C.; SANTELLO, G.A. Composição química e perdas totais de matéria seca na silagem de planta de soja. Acta Scientiarum - Animal Sciences, v.32, n. 1, p.19-26, 2010.

JOBIM, C.C. Ensilabilidade das plantas forrageiras e qualidade do volumoso conservado. 2008.

Disponível em:

$<$ http://www.iepec.com/noticia/ ensilabilidade-das-plantas-forrageiras.> Acesso em: 27 ago. 2011.

JOHNSON, H.E.; MERRY, R.J.; DAVIES, D.R.; KELL, D.B.; THEODOROU, M.K.; GRIFFITH, G.W. Vacuum packing: a model system for laboratory scale silage fermentations. Journal of Applied Microbiology, v.98, n.1, p.106-113, 2005.

KUNG JÚNIOR, L.; GRIEVE, D.B.; THOMAS, J.W.; HUBER, J.T. Added ammonia or microbial inocula for fermentation and nitrogenous compounds of alfafa ensiled at various percents of dry matter. Journal of Dairy Science, v.67, n.2, p.299-306, 1984.

KUNG JÚNIOR, L.; TAYLOR, C.C.; LYNCH, M.P.; NEYLON, J.M. The effect of treating alfalfa with Lactobacillus buchneri 40788 on silage fermentation, aerobic stability, and nutritive value for lactating dairy cows. Journal of Dairy Science, v.86, n.1, p.336-343, 2003.

McDONALD, P.; HENDERSON, N.; HERON, S. The biochemistry of silage. 2.ed. Marlow: Chalcombe, 1991. $339 \mathrm{p}$. 
Rev. Bras. Saúde Prod. Anim., Salvador, v.15, n.2, p.381-393 abr./jun., 2014 http://www.rbspa.ufba.br ISSN 15199940

MICKAN, F.J.; MARTIN, M.D; PILTZ, J.W. Silage Storage. In: KAISER, A.G.; PILTZ, J.W.; BURNS, H.M.; GRIFFITHS, N.W. (Eds.)

Successful Silage. 2.ed. Australia: Department of Primary Industries and Dairy Australia, 2004. p.217-252.

MOSS, B.R.; LIN, J.C.; WRIGHT, D.; WRIGHT, L.; McELHENNEY, W.H.; PREVATT, J.W.; DOROUGH, H.D. Milk production from cows fed corn, alfalfa or ryegrass silage ensiled in conventional, vacuum or packed systems. Professional Animal

Scientist, v.18, n.4, p.324-331, 2002.

MUCK, R.E.; FILYA, L.;

CONTRERAS GOVEA, F.E. Inoculant effects on alfalfa silage: in vitro gas and volatile fatty acid production. Journal of Dairy Science, v.90, n.6, p.51155125, 2007.

NATIONAL RESEARCH COUNCIL NRC. Nutrient requeriments of dairy cattle. 7.ed. Washington, D.C.: National Academy Press, 2001. 381p.

NEUMANN, M.; OLIVEIRA, M.R; ZANETE, P.M.; UENO, R.K.; MARAFON, F.; SOUZA, M.P.

Aplicação de procedimentos técnicos na ensilagem do milho visando maior desempenho animal. In: SIMPÓSIO SOBRE PRODUÇÃO E UTILIZAÇÃO DE FORRAGENS CONSERVADAS, 4., 2011, Maringá. Anais... Maringá: UEM/CCA/DZO, 2011. p.95-130.

PINTO, A.P.; MIZUBUTI, I.Y.; RIBEIRO, E.L.A.; FEY, R.; PALUMBO, G.R.; ALVES, T.C. Avaliação da silagem de bagaço de laranja e silagem de milho em diferentes períodos de armazenamento. Acta Scientarum. Animal Science, v.29, n.4, p.371-377, 2007.
RIBEIRO, K.G.; PEREIRA, O.G.; RIGUEIRA, J.P.S.; SOUZA, W.F.; ROSA, L.O.; SILVA, V.P. Perfil fermentativo de silagens mistas de estilosantes Campo Grande e capimelefante. In: REUNIÃO ANUAL DA SOCIEDADE BRASILEIRA DE ZOOTECNIA, 48., 2011, Belém. Anais... Belém: Sociedade Brasileira de Zootecnia 2011a.

RIBEIRO, K.G.; PEREIRA, O.G.; CEZÁRIO, A.S.; CAMPOS, A.F.; RUFINO, L.D.A.; CARDOSO, L.L. Composição bromatológica de silagens mistas de estilosantes Campo Grande e capim-elefante. In: REUNIÃO ANUAL DA SOCIEDADE BRASILEIRA DE ZOOTECNIA, 48., 2011, Belém. Anais... Belém: Sociedade Brasileira de Zootecnia, 2011b.

RODRIGUES, P.H.M.; ANDRADE, S.J.T.; ALMEIDA, L.F.S.; MEYER, P.M.; LIMA, F.R.; LUCCI, C.S. Inoculação Microbiana da Alfafa para Ensilagem sobre a Digestibilidade Aparente em Carneiros. Revista Brasileira de Zootecnia, v.30, n.6, p.1925-1930, 2001.

RODRIGUES, P.H.M.; ALMEIDA, L.F.S; LUCCI, C.S.; MELOTTI, L.; LIMA, F.R. Efeitos da adição de inoculantes microbianos sobre o perfil fermentativo da silagem de alfafa adicionada de polpa cítrica. Revista Brasileira de Zootecnia, v.33, n.6, p.1646-1653, 2004.

STATISTICAL ANALYSIS SYSTEM. SAS user's guide: statistics. Version 9.2. Cary, NC: SAS Institute, 2009.

SCHMIDT , R.J.; HU, W.; MILLS, J.A. KUNG JUNIOR, L. The development of lactic acid bacteria and Lactobacillus buchneri and their effects on the fermentation of alfalfa silage. Journal 
Rev. Bras. Saúde Prod. Anim., Salvador, v.15, n.2, p.381-393 abr./jun., 2014 http://www.rbspa.ufba.br ISSN 15199940

of Dairy Science, v.92, n.12, p.50055010, 2009.

SILVA, D.J., QUEIROZ, A.C. Análise de alimentos: métodos químicos e biológicos. 3.ed. Viçosa: Universidade Federal de Viçosa, 2002. 235p.

SNIFFEN, C.J., O'CONNOR, J.D., Van SOEST, P.J.; FOX, D.G.; RUSSEL, J.B. A net carbohydrate and protein system for evaluating cattle diets II. Carbohydrate and protein availability. Journal of Animal Science, v.70, n.11, p.3562-3577, 1992.

TILLEY, J.M.A.; TERRY, R.A. A twostate tehnique for in vitro digestion of forage crops. Journal of British

Grassland Society, v.18, n.2, p.104111, 1963.
VAN SOEST, P.J.; ROBERTSON, J.B.; LEWIS, B.A. Methods for dietary fiber, neutral detergent fiber, and no starch polysaccharides in relation to animal nutrition. Journal of Dairy Science, v.74, n.10, p.3583-3597, 1991.

WALKER, P.M.; FORSTER JÚNIOR, L.A. Case study: the evaluation of a vacuum storage method for high moisture distillers grain and its effect as a protein and energy supplement for beef cows. Professional Animal Scientist, v.24, n.6, p.648-655, 2008.

Data de recebimento: 23/07/2013

Data de aprovação: 16/06/1014 